\title{
TERRITÓRIO, CULTURA E NATUREZA EM SÍMBOLOS NACIONAIS: A REPRESENTAÇÃO ESPACIAL EM BANDEIRAS
}

\author{
TERRITORY, CULTURE AND NATURE IN NATIONAL SYMBOLS: \\ THE SPATIAL REPRESENTATION IN FLAGS
}

\author{
TERRITORIO, CULTURA Y NATURALEZA EN LOS SÍMBOLOS \\ NACIONALES: LA REPRESENTACIÓN ESPACIAL EN BANDERAS.
}

Tiago José BERG

Mestrando em Geografia, Rio Claro, IGCE, UNESP*

tiago_berg@yahoo.com.br

\begin{abstract}
Resumo
A bandeira, em conjunto com o brasão e o hino nacional são os três símbolos através dos quais um país independente proclama sua identidade e soberania. Em essência, eles servem como "totens modernos" - são signos que carregam uma afinidade especial para as nações que representam, distinguindo-as umas das outras, e reafirmando suas fronteiras de identidade. Eles projetam valores culturais associados a uma identidade política e à idéia de pertencimento a uma nacionalidade, uma comunidade política imaginada. Neste artigo, se examinam as bandeiras dentre os símbolos nacionais presentes, onde se encontra uma grande variedade de significações que envolvem a natureza, o território e a cultura como referências de espaços geográficos simbólicos associados a cada país ao longo do mundo. Argumenta-se que as bandeiras demonstram amplas possibilidades de interpretação dentro do campo científico, demandando maiores estudos para que se possa estreitar as relações entre "a geografia e representações simbólicas" como uma nova perspectiva da análise e decodificação das formas culturais de representação espacial.

Palavras-chave: Símbolos Nacionais, Natureza, Território, Cultura.

\footnotetext{
"Bolsista FAPESP - Este artigo é resultado das reflexões da dissertação de mestrado "Território, Cultura e Regionalismo: Aspectos Geográficos em Símbolos Estaduais Brasileiros", sob orientação da Prof. Dra. Bernadete Ap. C. de Castro Oliveira.
} 


\begin{abstract}
The flag, together with the coat of arms and the national anthem are the three symbols through which an independent country proclaims your identity and sovereignty. In essence, they serve as "modern totems" - signs that bear a special relationship to the nations they represent, distinguishing them from one another and reaffirming their identity boundaries. They project cultural values associated to a political identity and the idea of belonging to a nationality, an imagined political community. In this article, I examine the flags among the present national symbols, where them show a great variety of significances that embrace the nature, the territory and the culture as references of the symbolic geographical spaces associated to each country around the world. I argue that flags demonstrate wide possibilities of interpretation in the scientific field, requesting larger studies that can narrow the relationships between the "geography and symbolic representations" as a new perspective of the analysis and decode the cultural ways of spatial representation.
\end{abstract}

Key-Words: National Symbols, Nature, Territory, Culture.

\title{
Resumen
}

La bandera, en conjunto con el blasón y el himno nacional son los tres símbolos por medio de que un país independiente proclama su identidad y soberanía. En esencia, ellos sirven como "tótemes modernos" - son signos que llevan una afinidad especial a las naciones que ellos representan, diferenciandolas unas de otras y reafirmando sus fronteras de identidad. Ellos proyectan valores culturales asociados a una identidad política y la idea de pertenecer a una nacionalidad, una comunidad política imaginada. En esto artículo, examino las banderas entre los símbolos nacionales de la actualidad, dónde encuentro una gran variedad de significaciones que abarcan la naturaleza, el territorio y la cultura como referencias de espacios geográficos simbólicos asociados a cada país en el mundo. Argumento que las banderas demuestran posibilidades anchas de interpretación en el campo científico, señalando mayores estudios a fin de estrechar las relaciones entre la "geografía y las representaciones simbolicas", como una nueva perspectiva de análisis y de descifrar las formas culturales de representación espacial.

Palabras-Clave: Símbolos nacionales, Naturaleza, Territorio, Cultura.

\section{Introdução}

Símbolos nacionais portam-se como claras declarações de identidade. Em essência, eles servem como totens modernos (no sentido Durkheimiano) - signos que carregam uma afinidade especial para as nações que representam, distinguindo-as umas das outras e reafirmando suas fronteiras de identidade (CERULO, 1993). 
Eles remetem esses significados como um traço distintivo de um grupo ou comunidade em forma de unidade política, criando uma identidade associativa em que "se pode experimentar a consonância, a realização física da comunidade imaginada" $\left(\right.$ ANDERSON, 2005) ${ }^{1}$ através processo ritual. Dentro dessa perspectiva, como parte de tradições que parecem ou alegam ser mais antigas e que, muitas vezes são de origem bastante recente, Hobsbawm e Ranger (1997) concebem os símbolos nacionais como uma "tradição inventada" pelo nacionalismo político do século XIX. ${ }^{2}$ Tanto os movimentos nacionalistas, quanto os Estados "tinham todas as razões para reforçar, se pudessem, o patriotismo estatal com os sentimentos e símbolos da comunidade imaginária, onde e como eles se originassem e concentrá-los sobre si mesmos" (HOBSBAWM, 1990, p.111).

Conforme demonstra Estévez (2004, p.349) "ao se cantar o hino nacional [hastear a bandeira e/ou ostentar o brasão de armas] se recriam e reproduzem as lealdades a um sujeito coletivo [...] o sujeito coletivo, não se dissolve magicamente na nação, como que experimenta a nação em si mesmo". Quando experimenta a nação, o sujeito coletivo (o nós) entra em comunhão com essa identidade cultural transplantada para o âmbito nacional, pois, nas palavras de Stuart Hall (2005, p.59) “não importa quão diferentes seus membros possam ser em termos de classe, gênero ou raça, uma cultura nacional busca unificá-los numa identidade cultural, para representá-los todos como pertencendo à mesma grande família nacional”. É preciso lembrar que esta é uma característica intrínseca dos símbolos, pois eles projetam uma mensagem que é propositalmente e meticulosamente construída quando foram adotados ou escolhidos para se tornarem símbolos oficiais de uma nação; assim, eles não são projetados apenas para a população nacional, mas para um mundo além das fronteiras nacionais (CERULO, 1993).

\footnotetext{
${ }^{1}$ [...] "é uma comunidade política imaginada como intrinsecamente limitada e soberana" (ANDERSON, 2005 , p. 25), ou seja, o político se manifestando através das necessidades das fronteiras, da apropriação simbólica da natureza, dos elementos culturais e imaginários que circunscrevem e legitimam a nação.

${ }^{2}$ Por "tradição inventada" entende-se um conjunto de práticas, normalmente reguladas por regras tácita ou abertamente aceitas; tais práticas, de natureza ritual ou simbólica, visam inculcar certos valores e normas de comportamento através da repetição, o que implica automaticamente, uma continuidade em relação ao passado [o hino, a bandeira, o brasão].
} 
Essa mensagem projetada pelo símbolo pode ser analisada em duas vias. A primeira, através de seu conteúdo simbólico, que são as cores ou emblemas usados em uma bandeira; pode-se decifrar a mensagem de cada componente do símbolo isolando seus elementos e focando-se no significado e na percepção (geográfica) de cada um deles, que seria a análise semântica. Na segunda, estuda-se o desenho ou configuração de um símbolo, como por exemplo, de que forma as cores e emblemas ocupam posições adjacentes em uma bandeira, o número de faixas e suas secções, elementos heráldicos, etc. Quando se examina o significado carregado por estas estruturas (seu desenho ou configuração e a relação entre estas partes) emprega-se uma análise sintática dos símbolos.

O contraste metodológico das estruturas semânticas e sintáticas permite analisar os sentidos e valores que circunscrevem o espaço geográfico apropriado de forma sintética para se tornar um símbolo nacional; nesse contexto, ele pode ser decodificado a fim de revelar em seu conteúdo a importância que esses elementos (naturais e culturais) adquiriram para uma determinada comunidade imaginada em forma de nação.

Quando esses símbolos são ostentados no processo ritual, renovam-se os compromissos morais dos patriotas com a pátria simbolizada (re)construindo e (re)afirmando os elementos culturais, a natureza, as paisagens e os demais aspectos de caráter geográfico imaginados numa e para uma nação intrinsecamente limitada e soberana por seu território.

\section{Bandeiras}

Uma bandeira não se restringe à apenas um mero pedaço de pano que tremula ao vento; suas cores, formas, divisões e iconografia têm um sentido de ser, simbolizando e condensando elementos que representam um país soberano. Elas exaltam ou recusam valores e posições políticas (KANASHIRO, 2006), marcam determinado momento histórico e colocam em evidência conflitos e tensões de múltiplas identidades.

As bandeiras modernas começaram a surgir em meados do século XVI. Durante a revolta holandesa contra a Espanha (1567-1579), o príncipe Guilherme de Orange adotou uma bandeira tricolor horizontal simples, chamada de Prinsenvlag (semelhante a atual bandeira holandesa), que logo passou a figurar no pensamento ocidental como um 
emblema de liberdade. ${ }^{3}$ Essa associação teve forte influência para a confecção da bandeira tricolor nascida na Revolução Francesa (pós-1789) e outras nações passaram a copiar o mesmo desenho como símbolo de liberdade (nacional).

Até o século XIX, o uso de bandeiras em terra era limitado (sua presença era massiva nas navegações marítimas) e apenas alguns países tinham uma bandeira nacional. Mas as mudanças decorridas no começo daquele século, pela ascensão dos movimentos nacionalistas na Europa (principalmente no pós-1848), a independência das nações latino-americanas e as mudanças culturais que deram nascimento à idéia imaginária do Estado nacional e dele, a noção ocidental de soberania, é que os estandartes civis se tornaram a "bandeira nacional".

Da mesma forma que o brasão de armas se tornou o signo identificado com o governante e o Estado, também a bandeira nacional veio a ser tornar um símbolo no qual o povo podia se identificar, já que o conceito de bandeira nacional como um símbolo do povo aconteceu antes do Estado se tornar prevalecente, e em muitos casos a bandeira foi introduzida pelos líderes dos movimentos de independência, revolucionários ou estudantes e só depois adotada por um governo (SNAMIEROWSKI, 2004). Durante as independências nacionais do século XX, em especial no pós-guerra (1945), grande parte das nações do globo se tornou de facto independente e adotou para si mesma uma bandeira nacional. ${ }^{4}$

\section{Território, Cultura e Natureza}

Bandeiras são símbolos concretos que manifestam idéias abstratas. Todo símbolo tem um significante (que é o elemento sensível, perceptível por nós) e um significado, que é o seu conteúdo simbólico; para que haja um símbolo é necessário haver uma interconexão entre o significante e o significado. Os conteúdos significantes representam os valores associados aos elementos naturais e sociais, enquanto a

\footnotetext{
${ }^{3}$ SMITH, W. Flags through the ages and acoss the world, 1975 apud SNAMIEROWSKI (2004).

${ }^{4}$ Isso não significa que as possessões coloniais da África, Ásia, Oceania ou Caribe não tivessem uma bandeira própria antes disso; no caso dos protetorados britânicos, desde 1865 foram criadas bandeiras com a Union Jack em campo/fundo azul ou vermelho - isto é, a bandeira britânica no cantão/quadrilátero superior da bandeira, como ocorre atualmente com as bandeiras da Austrália e Nova Zelândia - em que se inseria um brasão de armas ou elementos associativos à uma determinada colônia ou protetorado.
} 
configuração gráfica e sua disposição sintática forma o imaginário do espaço geográfico. Luchiari (2001) ressalta que as paisagens construídas e valorizadas da sociedade revelam sua estrutura social e conformam lugares, regiões e territórios; a paisagem é materialidade, mas é ela que permite à sociedade a concretude de suas representações simbólicas.

Para a presente análise dos símbolos nacionais foram selecionadas algumas bandeiras de diversos países do mundo, objetivando desconstruir as idéias condensadas em cada uma delas a respeito das formas culturais de representação do território, da natureza e a cultura através da imaginação da paisagem e do mapa.

\section{A bandeira como paisagem}

Em 1965 a pequena colônia britânica de Gâmbia, na costa da África Ocidental ${ }^{5}$ conquistou sua independência e no mesmo ano adotou sua bandeira nacional (figura 1). As cores de suas faixas horizontais representam uma paisagem nacional no sentido "horizontal", avançando além de suas bases políticas. O azul representa o Rio Gâmbia, que flui por todo o país (mapa 1), fonte de vida para sua população. O vermelho representa o calor do sol africano e as savanas ao norte, enquanto o verde é uma associação feita à agricultura e à frescura das florestas tropicais ao sul. As faixas brancas reportam harmonia, unidade e paz entre os elementos naturais (FIREFLY, 2003; SNAMIEROWSKI, 2004; KINDERSLEY, 2005). Essa bandeira porta-se, assim, como uma representação da percepção ambiental que o povo de Gâmbia têm de seu espaço vivido, mesmo que ela não se circunscreva ao espaço político delimitado por sua fronteira com o Senegal e as nações vizinhas projetadas pelo símbolo.

$\mathrm{Na}$ África Oriental, as relações entre o território, população e natureza aparecem na bandeira da Tanzânia, adotada em 1964 (figura 2) - resultado da união política das cores de Tanganica (verde, amarelo e preto) e do arquipélago de Zanzibar (azul, preto e verde). O triângulo verde superior é uma referência ao espaço agrícola de Tanganica e o triângulo azul inferior representa a relação do arquipélago de Zanzibar com o mar e seus derivados, ambos estão secionados por uma faixa negra, denotando a união das populações (de origem negra) dos dois territórios, bordada pelas faixas douradas,

\footnotetext{
${ }^{5}$ Recomendo ao leitor que esteja em posse de um Atlas Geográfico atualizado para maiores detalhes.
} 
representando as riquezas minerais do país (FIREFLY, 2003; SNAMIEROWSKI, 2004; KINDERSLEY, 2005). Denota-se ainda que a forma como é disposta esta faixa na bandeira reforça a idéia de uma representação geográfica; sua costa litorânea possui ao norte uma orientação predominantemente no sentido nordeste-sudoeste, área onde se localiza o arquipélago de Zanzibar (mapa 2). Essa bandeira projeta as relações entre a população e os elementos naturais (cultivados e minerais), formando um recorte simbólico do espaço geográfico da Tanzânia. Nas palavras de Luchiari (2001, p.13) “(...) tomada isoladamente a paisagem é um vetor passivo. Somada ao valor social que lhe é atribuído, transforma-se em espaço, processo ativo da dinâmica social”.

A bandeira da Ucrânia, país do Leste Europeu, pressupõe uma "paisagem imaginada" como na vista de um quadro. Em 1848, o Conselho da Rutênia adotou as cores dourada e azul como símbolos nacionais (FIREFLY, 2003); foi com essas cores que a primeira bandeira bicolor surgiu em 1918, quando o país experimentou sua breve independência, ressurgindo após 1991 com o fim do regime soviético (figura 3). Para Snamierowski (2004) e Kindersley (2005) o azul alude aos céus ucranianos, assim como às montanhas (FIREFLY, 2003), o amarelo-dourado representa os vastos campos cobertos de grãos que compõem a paisagem agrícola do país (fotografia 1), um lugar de vivência e espaço comum percebido por seus habitantes - seria esta a paisagem nacional projetada pelo símbolo. Conforme relembra Tuan (1985, p.149) "uma grande região, tal como a do estado-nação, está além da experiência da maioria das pessoas, mas pode ser transformada em lugar - uma localização de lealdade apaixonada - através do meio simbólico da arte, da educação e da política".

O uso de cores em alusão aos elementos naturais do espaço físico é também outra forma de dar um sentido geográfico à bandeira nacional, mesmo que as formas ou os elementos ideológicos não coincidam com aquilo que é representado no seu desenho básico, fato que ocorre com a bandeira da Islândia. Como no caso dos outros países nórdicos, a bandeira islandesa (figura 4) deriva da "cruz escandinava" da bandeira dinamarquesa, conhecida como Dannebrog. ${ }^{6}$ Adotada em 1915, seu desenho é semelhante ao da Noruega, mas com as cores invertidas; o azul e o branco são as cores

\footnotetext{
6 Dannebrog em dinamarquês significa "bandeira dos dinamarqueses", apresentando uma cruz descentrada para a direita, característica de laços culturais comuns aos países escandinavos.
} 
da Islândia e o vermelho deriva dos noruegueses, de onde muitos de seus ancestrais originaram-se (SNAMIEROWSKI, 2004).

Entretanto, o sentido simbólico empregado mostra que para o povo islandês, o colorido de sua bandeira representa uma visão da paisagem de seu país. As cores são referências dos três elementos que compõem a ilha: fogo, gelo e água (KINDERSLEY, 2005). Ainda, de acordo com esse liame, o fundo azul representa o Oceano Atlântico, o branco as calotas polares e a neve que cobrem o país e o vermelho a lava dos vulcões (FIREFLY, 2003). Uma análise mais esmiuçada mostra que esse sentido simbólico dado ao espaço geográfico e imaginado através das cores em relação ao formato da bandeira apresenta uma justificação. O nome "Islândia" é um erro de tradução dos cartógrafos ibéricos, conforme relata Otero (2006, p.343) à cerca da nomeação da ilha no século XIII:

\begin{abstract}
Floki [Floki Vilgerdarson era um viking norueguês] subiu no alto de uma montanha e avistou um fiorde cheio de gelo. Ele o chamou de Isafjordur (o fiorde de gelo) e deu à ilha o nome de Island, que deve ser traduzido como "terra de gelo", pois em nórdico antigo "Is" significa gelo [...]. Por erro na tradução, nas cartas náuticas espanholas e portuguesas ela figurava como Islândia [...].
\end{abstract}

Com relação aos vulcões, a Islândia localiza-se no meio da dorsal meso-oceânica do Atlântico Norte, caracterizada por placas tectônicas divergentes e vulcanismos de fissura com lavas máficas ou básicas pouco viscosas (pobres em sílicas). Devido à essa baixa viscosidade, as erupções vulcânicas muito fluídas são capazes de escorrer por longas distâncias, dando sentido aos segmentos latitudinais e longitudinais da faixa vermelha apresentada na bandeira. Assim, a representação simbólica da bandeira islandesa contém as formas culturais da cruz escandinava, mas a justificação de suas cores é tomada no sentido de representar os elementos da natureza percebidos pelo povo islandês.

\title{
A bandeira como mapa
}

A bandeira da ilha de Nauru, adotada em 1968, fornece-nos um claro exemplo (figura 5). O azul representa a imensidão do Oceano Pacífico, enquanto a faixa amarela retrata a linha do Equador, no qual a ilha se situa geograficamente $\left(0^{\circ} 32^{\prime} \mathrm{S}\right.$ e $166^{\circ} 54^{\prime}$ 
E). Abaixo dela encontra-se uma estrela branca de doze pontas, representando a ilha e as doze tribos que originalmente a habitavam (FIREFLY, 2003; SNAMIEROWSKI, 2004; KINDERSLEY, 2005). A posição geográfica da pequena e isolada ilha de Nauru, na região da Micronésia, denota a expressão gráfica e o simbolismo desta bandeira, atuando como um "mapa simbólico" do país.

O Oblast $^{7}$ de Nagorno-Karabakh (ou Artsakh), um enclave regional autônomo de população majoritariamente armênio-cristã pertencente à República do Azerbaijão, país cuja maioria da população professa o islamismo, utiliza em sua bandeira uma representação territorial de sua separação da pátria-mãe (figura 6). A bandeira exibe as cores da Armênia, mas possuindo um sentido simbólico diferente desta: a faixa vermelha representa o sangue derramado para preservar a nação, o azul o amor pela liberdade e o laranja a sustentação (SNAMIEROWSKI, 2004). ${ }^{8}$ A faixa branca pontilhada voltada para o oeste é uma representação gráfica da separação da região em relação ao território da Armênia e a esperança de união com esta pátria; o desenho também evoca uma representação dos tapetes armênios (NOTHOLT, 1999). ${ }^{9}$ Esta bandeira configura-se como uma representação da separação geográfica do povo de Karabakh (Artsakh) em relação à Armênia pelo território do Azerbaijão (mapa 3).

Finalmente, ao condensar uma grande variedade de significações que envolvem o imaginário de natureza, cultura e território, a expressão gráfica projetada pelas bandeiras atua como uma representação simbólica dos elementos que circunscrevem a formação histórico-geográfica particular de cada nação.

\footnotetext{
${ }^{7} \mathrm{Na}$ hierarquia regional da União Soviética, as maiores unidades eram as 15 Repúblicas, que tinham poder teórico para se privar da união. Imediatamente abaixo destas estavam as Repúblicas Autônomas, com um grau mais alto de autonomia que os Oblasts, ou regiões autônomas [...] Quando a Transcaucásia foi incorporada ao Império Soviético em 1920-21, as fronteiras entre as Repúblicas do Azerbaijão, Armênia e Geórgia não foram imediatamente determinadas. Este foi um dos muitos problemas para a delimitação entre as fronteiras do Azerbaijão e da Armênia, notavelmente à questão do status das regiões de Nagorno-Karabakh e Nakhichevan. [...] Assim, essa questão foi finalmente resolvida, durante as discussões de 1922, em que [os Soviéticos determinaram] o status de Karabakh dentro da República Socialista Soviética Azerbaijani (CORNELL, 1997).

${ }^{8}$ Na bandeira da Armênia o azul representa o "céu" e o laranja a "coragem" (SNAMIEROWSKI, 2004).

${ }^{9}$ Ver: NOTHOLT, S. Description of the flag of Artsakh (Nagorno-Karabakh), 1999. In: Flags of the World Web Site, disponível em: <http://www.fotw.us/flags/az-artsa.html>, acesso em 10 de novembro de 2007.
} 


\section{Considerações Finais}

O presente artigo procura contribuir para uma nova perspectiva na análise da relação entre espaço e cultura, auxiliando o conhecimento já produzido na área da geografia cultural, que nas últimas décadas têm se interessado pelas questões associadas à identidade, quesitos esses de caráter multidisciplinar e que também envolvem as representações simbólicas.

Argumento que, da mesma forma que um mapa representa em sua escala o espaço concreto no plano cartesiano, as bandeiras analisadas atuam como projeções gráficas de espaços geográficos simbólicos em escala nacional, associando e condensando os elementos naturais e sociais presentes no imaginário do território.

Símbolos nacionais são ícones que carregam múltiplos valores culturais, sinais de reconhecimento mútuo entre os membros de um grupo (CLAVAL, 2006) associados a uma identidade coletiva e alicerçados numa trama territorial formada pela sociedade e natureza, (re)produzindo e (re)afirmando a idéia de pertencimento à uma determinada comunidade política imaginada intrinsecamente limitada e soberana (ANDERSON, 2005) através do processo ritual.

Assim, as bandeiras demonstram amplas possibilidades de análise e interpretação dentro do campo científico, demandando maiores estudos para que se possa estreitar as relações entre "a geografia e representações simbólicas" como uma nova perspectiva da análise e decodificação das formas culturais de representação espacial.

\section{Referências Bibliográficas}

ANDERSON, B. Comunidades imaginadas. Lisboa: Edições 70, 2005.

CERULO, K. A. Symbols and the World System: National Anthems and Flags. Sociological Forum, v. 8 (2), p.243-271, 1993. 
CLAVAL, P. Comunicação, diferenciação de culturas e organização do espaço: noçõeschave. In. SARMENTO, J.; AZEVEDO, A. F. de; PIMENTA, J. R. (Org.) Ensaios de Geografia Cultural. Porto: Livraria Editora Figueirinhas, 2006.

CORNELL, S. E. Undeclared War: The Nagorno-Karabakh conflict reconsidered. Journal of South Asian and Middle Eastern Studies. v. 20 (4), p. 1-24, 1997.

ESTÉVEZ. M. G. El amor a la patria y a la tribu: las retóricas de la memoria incómoda. Revista de Antropologia, São Paulo: USP, v. 47 (2), p. 345-377, 2004.

FIREFLY. Guide to the flags of the world. London: Firefly Books, $1^{\text {st }}$ ed. 2003.

HALL, S. A identidade cultural na pós-modernidade. Rio de Janeiro: DP\&A, $10^{\mathrm{a}}$ ed. 2005.

HOBSBAWM, E. Nações e nacionalismo desde 1780: programa, mito e realidade. Rio de Janeiro: Paz e Terra, 1990.

; RANGER, T. (org). A invenção das tradições. Rio de Janeiro: Paz e

Terra, $3^{\text {a }}$ ed. 1997.

KANASHIRO, M. Bandeiras e os símbolos da política. Comciência, 10 de junho de 2006.

$<$ http://www.comciencia.br/comciencia/handler.php? section=8\&edicao=11\&id=80>, acesso em 21 de junho de 2006.

KINDERSLEY. Complete Flags of the world. London: Dorling Kindersley Limited, 2005. 
LUCHIARI, M. T. D. P. A (re)significação da paisagem no período contemporâneo. In: CORRÊA, R. L.; ROSENDAHL, Z. Paisagem, imaginário e espaço. Rio de Janeiro: EDUERJ, 2001.

OTERO, E. A origem dos nomes dos países. São Paulo: Panda Books, $1^{\text {a }}$ ed. 2006.

TUAN, Y. F. Geografia Humanística. In: CHRISTOFOLETTI, A. (org). Perspectivas da Geografia. São Paulo: Difel, 1985.

ZNAMIEROWSKI, A. The world encyclopedia of the flags. London: Lorenz Books, 2004. 


\section{ANEXOS}

Figura 1: Bandeira de Gâmbia. Mapa 1: Extensão longitudinal de Gâmbia, África.
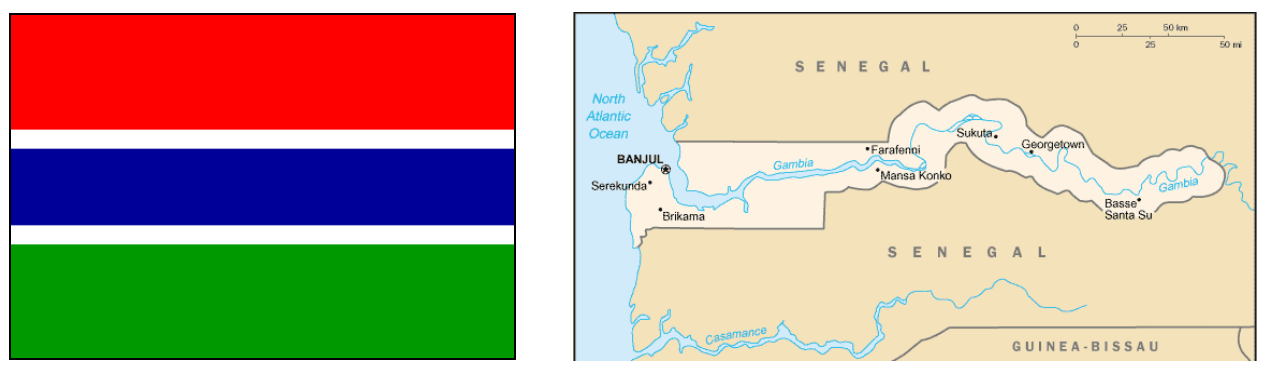

Figura 2: Bandeira da Tanzânia. Mapa 2: Tanzânia, no detalhe o arquipélago de Zanzibar.
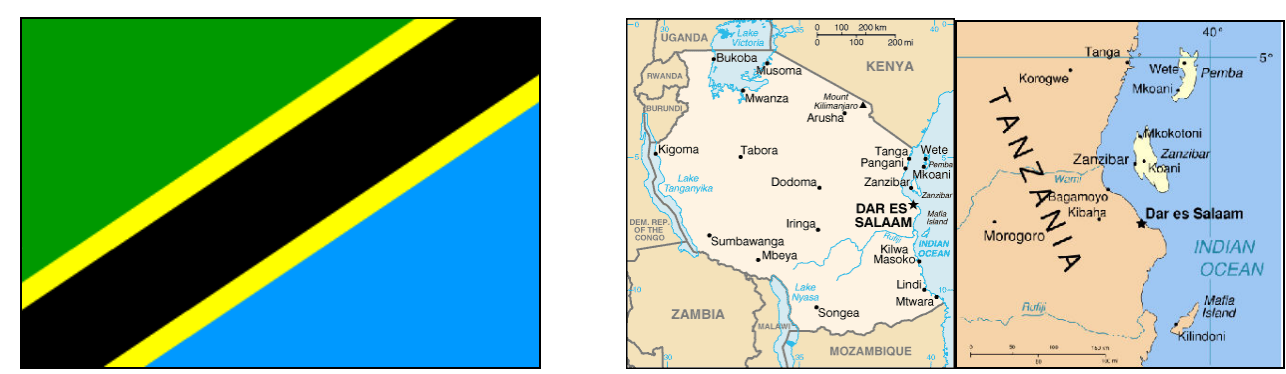

Figura 3: Bandeira da Ucrânia. Fotografia 1: Campo de trigo. Figura 4: Bandeira da Islândia. 


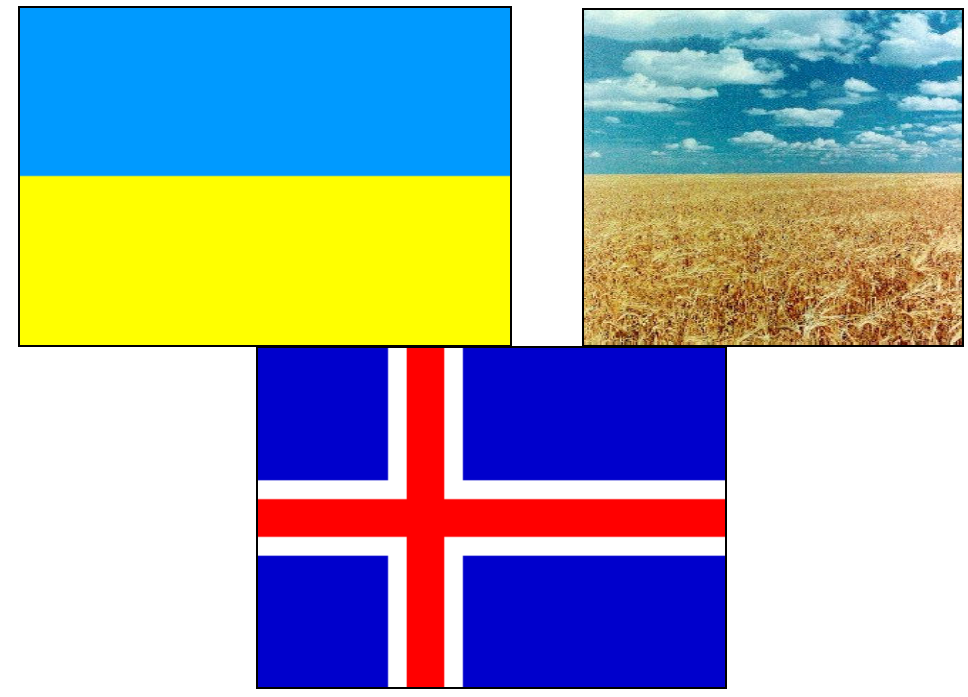

Figura 5: Bandeira de Nauru. Figura 6/Mapa 3: Bandeira e mapa com destaque em laranja do Oblast de Nagorno-Karabakh (Artsakh) entre a República do Azerbaijão e República da Armênia.
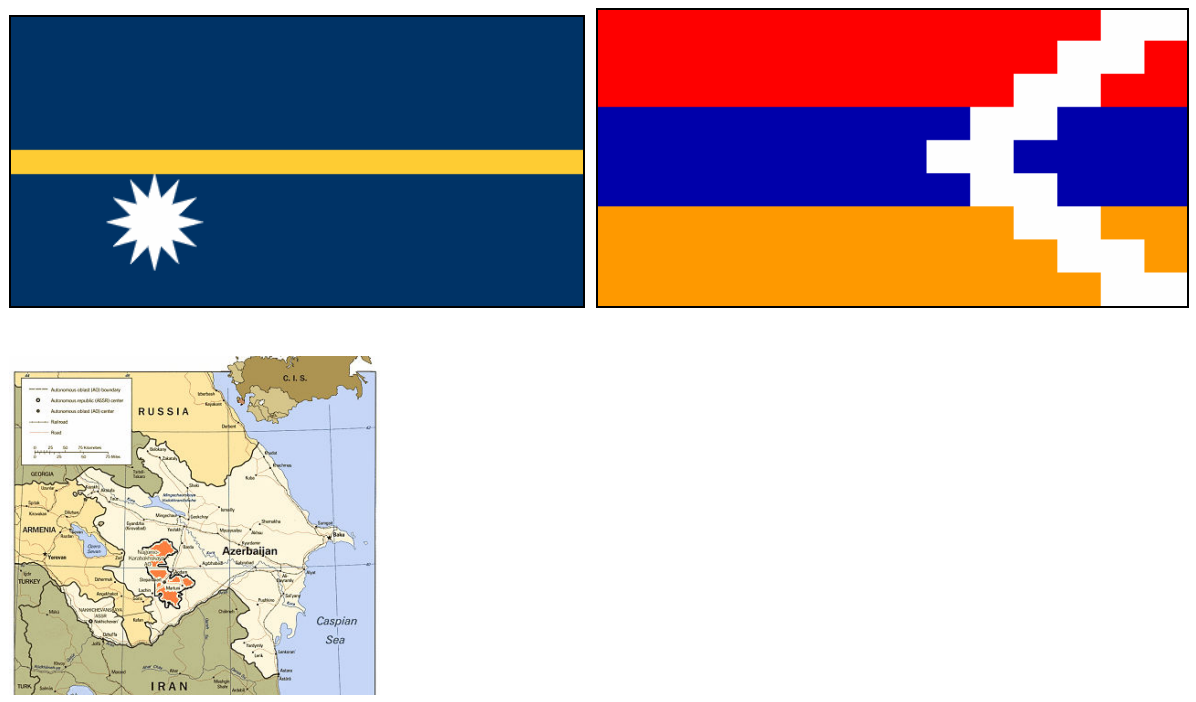
Recebido para publicação em maio de 2008 Aprovado para publicação em junho de 2008 